DOI : https://doi.org/10.24123/jbt.v5i2.4714

\title{
ANALISIS COMPETITIVE ADVANTAGE MELALUI PENDEKATAN RELATIONAL CAPITAL DAN SUPPLY CHAIN INTEGRATION
}

\author{
Agatha Christy Wahyono ${ }^{1}$, Kusdi Raharjo ${ }^{2}$ \\ ${ }^{1}$ Politeknik Ubaya; Surabaya, Indonesia, ${ }^{2}$ Universitas Brawijaya; Malang, Indonesia \\ Email : agathacw@staff.ubaya.ac.id ${ }^{1}$, kusdi_rahadjo@gmail.com ${ }^{2}$
}

\begin{abstract}
This research aims to examine the effect of relational capital to competitive advantage through supply chain integration. Research method in this study was explanatory research with a quantitative approach. This Research method used explanatory research with a quantitative approach. The object of this research was in four districts of East Java at Nganjuk, Kediri, Malang and Probolinggo which are centers of onion production that have the similar environmental conditions. The sampling method in this study used multistage proportional random sampling. There were 200 respondents as a sample of this research. Data analysis usedpath analysis method by software SPSS 23. The results showed that the relational capital has a positive but not significant effect on the supply chain integration and relational capital has a positive and significant effect on the competitive advantage.
\end{abstract}

Keyword : Agroindustry, Relational Capital, Shallot, Supply Chain Integration,
Competitive Advantage

\section{Pendahuluan}

Pandemi, globalisasi dan revolusi industri 4.0 yang mengarah kedigitalisasi adalah tiga hal yang saat ini sedang marak terjadi. Ketiga hal ini seakan menjadi penentu arah kehidupan manusia saat ini, termasuk didalamnya adalah kegiatan bisnis. Sebagai pelaku bisnis dituntut untuk mampu mengikuti perubahan yang terjadi dengan begitu dinamis. Untuk dapat mengikuti dan bertahan di era saat ini pun diperlukan beberapa kemampuan. Kemampuan yang dimiliki, juga harus bisa membuat pelaku mencapai suatu keunggulan yang kompetitif. Salah satu sektor bisnis yang mengalami persaingan yang cukup kompetitif adalah sektor pertanian.

Sektor ini menarik perhatian banyak pihak (pesaing dan pelaku usaha baru) baik dari dalam maupun luar negeri sehingga perlu adanya peningkatan daya saing pada sektor ini agar tercipta keunggulan kompetitif. Peningkatan daya saing produk pertanian telah menjadi perhatian utama pemerintah oleh sebab itu perlu adanya penentuan strategi yang 
tepat agar dapat memenangkan persaingan, sehingga pada akhirnya pelaku usaha dapat menjalankan usahanya sesuai dengan apa yang diharapkan.

Untuk mencapai keunggulan kompetitif melalui sumber daya manusia pada sektor pertanian, perlu adanya pemanfaatan dan pengembangan sumber modal usaha yaitu, relational capital atau modal relasional (Pramundityo, 2013). Relational capital merupakan hubungan yang dijalin pelaku usaha dengan pihak-pihak lainnya pada proses bisnis yang dilakukan termasuk proses distribusi yang meliputi pelanggan, pemasok, partner dan regulator (De Castro, et.al, 2004). Dari hubungan yang terbentuk secara baik dan dilakukan secara terus menerus, kemampuan dalam berelasi akan mempengaruhi daya saing termasuk menghasilkan ide-ide kreativitas dan juga menciptakan keunggulan kompetitif bagi pelaku usaha di berbagai sektor (Ngah dan Ibrahim, 2009). Dalam proses distribusi, dimensi modal relasional berpengaruh terhadap peningkatan kinerja rantai pasok karena relasi yang dijalin dengan baik antara pelaku usaha dengan mitranya akan mempermudah dan melancarkan proses distribusi karena terintegrasi dengan baik antar satu dengan yang lainnya.

Akan tetapi, keunggulan kompetitif bawang merah di Indonesia belum sepenuhnya tercapai karena dari segi harga, bawang merah lokal memiliki harga yang cukup tinggi jika dibanding dengan harga bawang merah impor. Penyebab harga bawang merah lokal lebih tinggi dibanding dengan bawang merah impor adalah panjangnya rantai distribusi bawang merah, seperti yang terlihat pada gambar 1.1. Menurut Gunawan (2016), semakin panjang rantai distribusi suatu produk maka semakin tinggi harga produk tersebut. Hasil penelitian yang dilakukan oleh Rasoki et al. (2016) menunjukkan bahwa sistem rantai pasok yang terjadi dalam pemasaran bawang merah belum efisien. Hal ini menyebabkan belum tercapainya keunggulan kompetitif produk bawang merah karena produk menjadi lebih mahal dan lebih lama sampai di tangan konsumen (Gunawan, 2016 dalam Tribun News). Untuk itu perlu adanya penerapan rantai pasok yang terintegrasi dengan baik agar sistem distribusi dapat berjalan dengan lebih efektif dan efisien.

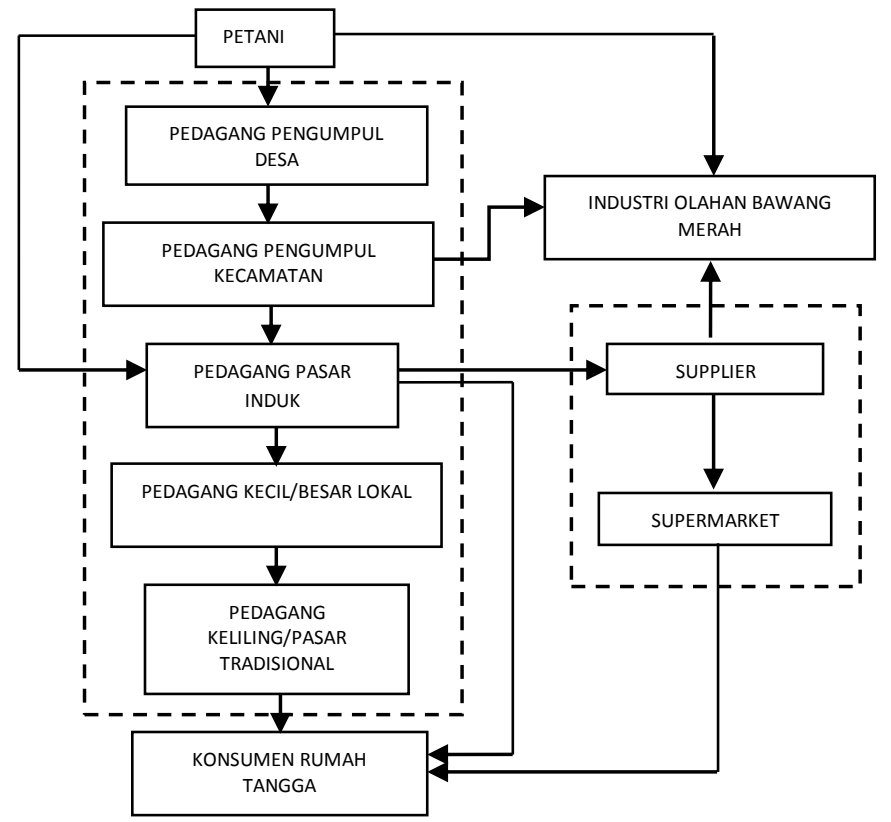

Sumber : Departemen Pengembangan Akses Keuangan dan UMKM BI, 2013

Gambar 1.1 Jalur Distribusi Bawang Merah 
Selain itu, permasalahan lain yang menyebabkan belum adanya daya saing pada komoditas bawang merah sehingga keunggulan kompetitif belum tercipta adalah rendahnya kualitas sumber daya manusia (SDM) petani. Rendahnya SDM petani menyebabkan petani sulit untuk menyerap pengetahuan dan keterampilan dalam hal produktivitas usaha, yang berpengaruh terhadap tingkat produktivitas. Oleh sebab itu, Peneliti tertarik untuk meneliti dan berusaha untuk membantu menyelesaikan permasalahan mengenai keunggulan kompetitif bawang merah di Jawa Timur dengan menggunakan variabel Relational Capital dan Supply chain integration. Penelitian ini bertujuan untuk menciptakan keunggulan kompetitif pada petani komoditas bawang merah melalui peningkatan kualitas sumber daya manusia berupa relational capital melalui rantai pasok integratif yang efektif dan efisien sehingga tercipta rantai pasok yang responsif dan memiliki keunggulan kompetitif. Didukung oleh penelitian dari Flynn et al. (2010) dan Rohaizat Baharun et. al (2012) yang menyatakan bahwa competitive advantage dipengaruhi secara positif dan signifikan oleh relational capital melalui supply chain integration dan supply chain responsiveness sehingga peneliti menggunakan variabel tersebut untuk melakukan penelitian ini.

Tujuan penelitian ini adalah untuk menganalisis 1) pengaruh relational capital terhadap competitive advantage; 2) pengaruh relational capital terhadap supply chain integratif dan 3) pengaruh relational capital terhadap competitive advantage melalui supply chain integratif.

\section{Kerangka Teori \\ Resource Based View (RBV)}

Resource Based View menjelaskan bahwa sumber daya dan kemampuan perusahaan harus berharga, langka, sulit untuk ditiru dan perusahaan memiliki sumber daya komplementer untuk meningkatkan dan memaksimalkan kemampuan. Hal ini sangat berguna dalam mendorong keunggulan kompetitif yang berkelanjutan. (Barney, 1991). Asumsi dasar RBV adalah bahwa sumber daya dalam perusahaan tergabung menjadi satu dan kapabilitas yang mendasari produksi tidak sama satu dengan yang lainnya (Collis, 1991). Oleh karena itu, competitive advantage yang berdasarkan sumber daya dan kapabilitas lebih sustainable daripada yang didasarkan product/market positioning (Hitt et al., 2001).

\section{Konsep Daya Saing}

Pendekatan yang sering digunakan untuk mengukur daya saing suatu komoditi adalah faktor keunggulan komparatif (comparative advantage) dan faktor keunggulan kompetitif (compepetitive advantage). Keunggulan kompetitif (competitive advantage) merupakan alat untuk mengukur daya saing suatu aktivitas berdasarkan pada kondisi perekonomian aktual atau harga pasar, dimana harga yang terjadi telah dipengaruhi oleh kebijakan pemerintah (Boossabong dan Taylor 2009). Keunggulan kompetitif suatu negara ditentukan oleh empat faktor yaitu kondisi faktor sumberdaya (factor condition), kondisi permintaan (demand condition), industri terkait dan industri pendukung (related and supporting industry), persaingan, struktur dan strategi perusahaan (firm strategy, structure and rivalry). Keempat faktor penentu tersebut didukung oleh faktor eksternal yang terdiri atas peran pemerintah (government) dan terdapatnya kesempatan (chance events). 


\section{Modal Relasional (Relational Capital)}

Relational capital merupakan suatu kemampuan untuk membangun suatu hubungan yang terjalin dengan baik antara perusahaan dengan investor, pelanggan, pemasok, pemerintah, ataupun masyarakat. Relational capital mewakili hubungan kerjasama dan strategic change patners (Roos dan Roos, 1997). Untuk alasan ini, aset yang diusulkan dalam model dan yang membentuk modal relasional perusahaan, karena mengacu pada hubungan dan membangun jaringan (yaitu, hubungan dengan pelanggan dan pemasok, dukungan untuk hubungan informal), akan dipelajari dari pandangan pengusaha dan terkait dengan kinerja.

\section{Sumber Daya Rantai Pasok}

Menurut Van der Vorst (2006), manajemen rantai pasok adalah integrasi dari rencana, koordinasi dan kontrol terhadap seluruh proses bisnis dan aktivitas dalam rantai pasok. Hal terpenting dalam dalam manajemen rantai pasok adalah saling berbagi informasi. Aliran material, kas, dan informasi merupakan keseluruhan elemen dalam rantai pasok yang perlu diintegrasikan (Chen et al. dalam Anatan dan Ellitan 2008). Integrasi dan kolaborasi merupakan aspek kunci dari manajemen rantai pasok.

\section{Supply Chain Integration}

Rantai pasok integratif merupakan integrasi strategis baik internal dan eksternal organisasi (Flynn, et al., 2010) dan mengukur sejauh mana mitra yang terlibat didalam rantai pasok bekerja bersama-sama untuk mendapatkan hasil yang saling menguntungkan (O'Leary-Kelly dan Flores, 2002). Menurut Ghai (2012), integrasi rantai pasok dapat meningkatkan daya saing melalui beberapa manfaat berikut, yakni memberikan informasi kepada petani untuk menanam sesuai kebutuhan pasar dan memperoleh harga yang lebih baik.

\section{Metode Penelitian Jenis Penelitian}

Jenis penelitian dalam penelitian ini adalah explanatory research dengan pendekatan kuantitatif. Penelitian ekplanatori merupakan jenis penelitian yang menekankan hubungan kausalitas atau sebab akibat antara dua atau lebih variabel yang saling mempengaruhi. Pendekatan dalam penelitian ini menggunakan pendekatan kuantitatif. Menurut Sugiyono (2010:14), pendekatan kuantitatif yaitu pendekatan yang berlandaskan pada filsafat positivism. Metode penelitian yang digunakan dalam penelitian ini adalah dengan menggunakan metode survei. Metode survei digunakan dalam penelitian ini karena penelitian ini mengunakan kuesioner sebagai instrumen pada sampel tertentu untuk memperoleh data yang akan dianalisis sebagai pengujian hipotesis.

\section{Lokasi Penelitian}

Lokasi penelitian dalam penelitian ini memilih lokasi di Kabupaten Nganjuk, Kabupaten Probolinggo, Kabupaten Kediri dan Kabupaten Malang. Pemilihan lokasi penelitian dengan pertimbangan bahwa keempat Kabupaten tersebut merupakan empat Kabupaten sentra penghasil bawang merah terbesar di Provinsi Jawa Timur sehingga peneliti mengganggap bahwa sampel yang dipilih sebagai responden cukup representatif dan dapat menjawab permasalahan penelitian untuk analisis data dan menjawab hipotesis penelitian. 


\section{Populasi}

Populasi pada penelitian ini adalah semua petani yang tergabung didalam Gabungan Kelompok Tani di desa-desa yang sudah dipilih di masing-masing Kabupaten. Total populasi dari data sekunder yang didapat berjumlah 2390 petani bawang merah, dengan rincian:

Tabel 2 Jumlah Petani Di Empat Kabupaten Yang Menjadi Tempat Penelitian

\begin{tabular}{cc}
\hline Wilayah & Populasi \\
\hline Kabupaten Nganjuk & 1256 \\
Kabupaten Kediri & 597 \\
Kabupaten Malang & 297 \\
Kabupaten Probolinggo & 240 \\
Jumlah & 2390 \\
\hline
\end{tabular}

(Sumber data : Dinas ketahanan pangan dan pertanian 2018)

\section{Sampel}

Metode sampling dalam penelitian ini menggunakan multistage proportional random sampling. Multistage merupakan pengambilan sampel dalam dua tahap atau lebih (Nazir, 2014:243). Penelitian ini menggunakan multistage dikarenakan peneliti tidak dapat mengidentifikasi jumlah populasi dengan mudah dan jumlah populasinya sangat besar. Adanya kesulitan dalam mengidentifikasi jumlah populasi yang sangat besar, ukuran sampel dalam penelitian ini ditentukan dengan menggunakan rumus Roscoe. Rumus Roscoe yaitu minimal 10 kali jumlah variabel yang diteliti dan kelipatannya (Sugiyono, 2010:124) dengan tingkat derajat kesalahan sebesar 5\%. Berdasarkan perhitungan rumus roscoe maka didapat ukuran sampe sebanyak 200 responden. Penelitian ini menggunakan 50 kali jumlah variabel, yaitu 50 x $4=200$ responden.

\section{Teknik Pengambilan Sampel}

Teknik pengambilan sampel dilakukan dengan berbagai tahap (multistage).

Tabel 3. Teknik Pengambilan Sampel

\begin{tabular}{lllllcc} 
No & Kabupaten & Kecamatan & \multicolumn{1}{c}{ Desa } & Gapoktan & $\begin{array}{c}\text { Jumlah } \\
\text { Anggota } \\
\text { Gapoktan }\end{array}$ & Sampel \\
\hline 1. & Nganjuk & Rejoso & Ngadiboyo & $\begin{array}{l}\text { Mandiri } \\
\text { Berkah } \\
\text { Mulya }\end{array}$ & 1256 & 105 \\
2. & Kediri & Badas & Sekoto & $\begin{array}{l}\text { Karya } \\
\text { Bakti }\end{array}$ & 297 & 50 \\
3. & Malang & Ngantang & Purworejo & $\begin{array}{l}\text { Harapan } \\
\text { Jaya }\end{array}$ & 240 & 20 \\
4. & Probolinggo & Dringu & Watuwungkuk & & 2390 & 200 \\
\hline
\end{tabular}

(Sumber: Diolah Peneliti, 2021) 
Jumlah sampel dan nama sampel dipilih dengan cara acak menggunakan aplikasi Microsoft Excel. Nama sampel, jumlah sampel dan GAPOKTAN yang diperoleh dari Dinas Pertanian masing-masing daerah, dimasukkan kedalam Microsoft Excel sesuai dengan yang diberikan oleh Dinas Pertanian. Kemudian, dengan menggunakan fungsi RANDBETWEEN dan rumus =RANDBETWEEN $(1 ;$ jumlahsampel/nama petani $)$ atau $==$ RANDBETWEEN(drag dari nama pertama hingga akhir) - Enter. Maka didapat sampel petani yang telah teracak.

\section{Teknik Pengumpulan Data}

Teknik pengumpulan data dalam penelitian ini menggunakan data primer dan data sekunder. Data primer berupa data yang didapat dari hasil survei dengan menggunakan kuisioner dan didukung dengan wawancara untuk memperkuat hasil yang diperoleh. Data sekunder berupa data-data pendukung awal yang diperoleh langsung dari Dinas Pertanian dan Hortikultura setiap kabupaten dan data-data yang diperoleh melalui search engine.

\section{Uji Validitas}

Suatu instrumen yang valid mengukur apa yang seharusnya diukur, mengukur apa yang hendak diukur (Morissan, 2016:103). Mengukur validitas membutuhkan penilaian yang cermat dan teliti. Valid atau tidaknya instumen dapat diketahui dari koefisien korelasi. product moment menunjukkan $r \geq 0,30$ (Indrianto, 2009: 77). Uji validitas bertujuan untuk menentukan tingkat kemampuan suatu indikator dalam pengukuran variabelnya.

\section{Uji Reliabilitas}

Reliabilitas merupakan indikator tingkat keandalan atau kepercayaan terhadap suatu hasil pengukuran. Suatu pengukuran dapat dikatakan reliabel atau memiliki keandalan jika konsisten dapat memberikan jawaban yang sama. Suatu pengukuran yang sama sekali tidak dapat diandalkan berarti tidak mampu mengukur apapun (Morissan, 2016:99).

Uji reliabilitas dapat menggunakan rumus koefisien alpha atau disebut alpha crobach $(\alpha)$ dengan nilai lebih besar dari 0. Dasar pengambilan keputusan apakah suatu pengukuran reliabel atau tidak adalah alpha crobach. Jika nila alpha crobach lebih besar dari 0.6 maka dapat disebut reliabel dan sebaliknya jika nilai alpha crobach lebih kecil dari 0.6 maka tidak reliabel (Indrianto, 2009: 90).

\section{HASIL DAN PEMBAHASAN}

\section{Hipotesis Penelitian}

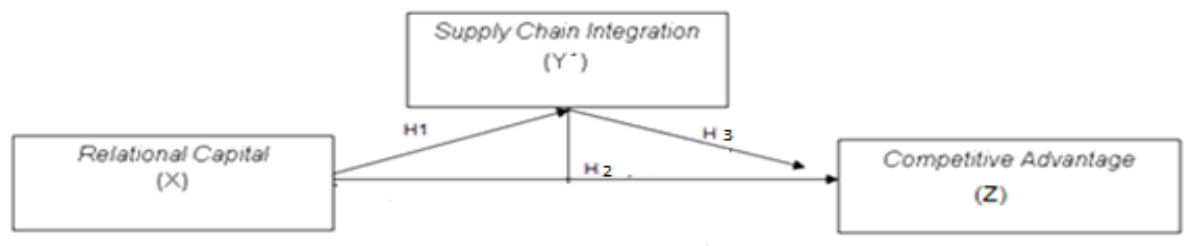

Gambar 1. Model Hipotesis Penelitian

(Sumber: Diolah Peneliti, 2021)

Berdasarkan latar belakang, rumusan masalah, tujuan penelitian serta penjelasan kajian teoritik dan data empiris penelitian terdahulu. Maka hipotesis yang diajukan dalam penelitian ini adalah sebagai berikut: 
H1 : Relational Capital berpengaruh terhadap Supply Chain Integration.

$\mathrm{H} 2$ : $\quad$ Relational Capital berpengaruh terhadap Competitive Advantage

H3 : Relational Capital berpengaruh terhadap Competitive Advantage melalui Suppy Chain Integration.

Tabel 4. Hasil Analisis Jalur Pengaruh (X terhadap Y, X terhadap Z)

\begin{tabular}{cccccc}
\hline $\begin{array}{c}\text { Variabel } \\
\text { Bebas }\end{array}$ & $\begin{array}{c}\text { Variabel } \\
\text { Terikat }\end{array}$ & $\begin{array}{c}\text { Standardized } \\
\text { Beta }\end{array}$ & $\begin{array}{c}\mathbf{t} \\
\text { hitung }\end{array}$ & $\begin{array}{c}\mathbf{P}- \\
\text { value }\end{array}$ & Keterangan \\
\hline $\mathrm{X}$ & $\mathrm{Y}$ & 0,107 & 1,519 & 0,130 & $\begin{array}{c}\text { Tidak } \\
\text { Signifikan }\end{array}$ \\
$\mathrm{X}$ & $\mathrm{Z}$ & 0,282 & 4,213 & 0,000 & Signifikan \\
\hline R square $\left(\mathrm{R}^{2}\right) 1$ & $: 0,012$ & & &
\end{tabular}

(Sumber : diolah oleh peneliti, 2021)

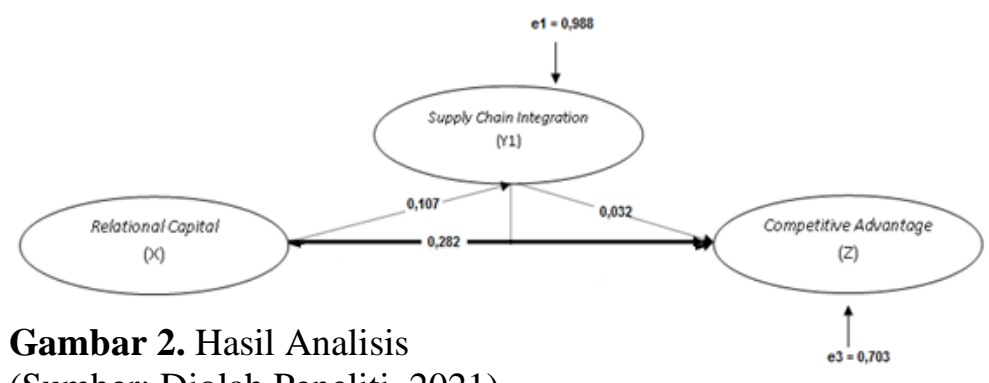

(Sumber: Diolah Peneliti, 2021)

Ket : ............... Jalur yang tidak signifikan

Jalur yang signifikan

Pengaruh Tidak Langsung Relational Capital terhadap Competitive Advantage melalui Supply Chain Integration.

Perhitungan besarnya pengaruh Supply Chain Integration sebagai variabel intervening adalah sebagai berikut:

Direct Effect (pengaruh langsung) Relational Capital terhadap Competitive Advantage sebesar 0,282

Indirect Effect $(\mathrm{IE}) \quad=\mathrm{PYX} \times \mathrm{PZY}$

$=0,107 \times 0,032$

$\begin{aligned} \text { Total Effect }(\mathrm{TE}) & =0,003 \\ & =\mathrm{PZX}+(\mathrm{PYX} \times \mathrm{PZY})\end{aligned}$

$=0,282+(0,107 \times 0,032)$

$=0,285$

Tabel 5. Pengaruh Tidak Langsung

\begin{tabular}{|c|c|c|}
\hline $\begin{array}{c}\text { Hubungan } \\
\text { Variabel }\end{array}$ & $\begin{array}{c}\text { Pengaruh Tidak } \\
\text { Langsung }\end{array}$ & $\begin{array}{c}\text { Total } \\
\text { Pengaruh }\end{array}$ \\
\hline $\mathrm{X}-\mathrm{Y}-\mathrm{Z}$ & $0,282+(0,107 \times 0,032)$ & 0,285 \\
\hline
\end{tabular}

\section{Relational Capital}

Hasil uji statistik deskriptif diperoleh bahwa variabel Relational Capital yang terdiri dari 4 indikator dan 5 item memiliki nilai rata-rata sebesar 3,08 yang dikategorikan baik. 
Nilai tersebut menunjukkan bahwa Relational Capital yang terjalin antara petani bawang merah dengan para mitranya seperti pemasok sarana produksi pertanian, bibit, pestisida dan juga konsumen terjalin dengan cukup baik meskipun belum terjalin secara maksimal. Relational Capital yang terjalin dengan baik ditunjukkan dalam hal adanya kepercayaan yang terbangun anatar petani dengan mitranya. Kepercayaan ini terjadi saat petani dan mitra mengalami masalah, maka kedua pihak akan percaya bahwa mereka saling membantu dalam mengatasi permasalahan yang terjadi. Selain itu, petani dan mitra samasama percaya bahwa kedua pihak akan saling menepati janji yang telah disepakati bersama dan percaya akan kemampuan kerja masing-masing pihak. Hubungan atau relasi yang baik juga terjadi karena adanya kerjasama yang cukup baik antara petani dan mitranya serta kerjasama tersebut terjadi dengan cukup menguntungkan. Dapat disimpulkan bahwa relasi yang terjadi antara petani dan mitranya sudah berjalan dengan cukup baik dilihat dari interaksi yang terjadi, adanya respect antar petani dengan mitra, adanya kepercayaan dan kerjasama yang terjalin dengan cukup baik antara petani dengan mitanya .

\title{
Supply Chain Integration
}

Variabel Supply Chain Integration (Y) yang terdiri dari 2 indikator dan 4 item memiliki nilai rata-ratanya sebesar 3,00 yang dikategorikan cukup. Dari pemaparan analisis deskriptif dapat dilihat bahwa antara petani bawang merah dan mita secara bersama-sama memantau proses bertanam dengan cukup baik. petani dan mita secara bersama-sama memantau proses panen dikategorikan cukup dan memiliki nilai rata-rata paling rendah, petani mengikuti pelatihan teknis yang diselenggarakan mitra dengan cukup baik, dan mitra dagang cukup membantu memperluas pemasaran bawang merah hingga sampai ketangan konsumen akhir. Maka dapat disimpulkan bahwa monitoring process yang dilakukan petani dengan mitra dikategorikan cukup dan jointly improve production yang dilakukan petani dengan mitra dikategorikan cukup.

\section{Competitive Advantage}

Variabel Competitive Advantage ( $\mathrm{Z}$ ) yang terdiri dari 2 indikator dan 4 item memiliki nilai rata-ratanya sebesar 3,51 yang dapat dikategorikan baik. Dari pemaparan analisis deskriptif dapat dilihat bahwa kualitas bawang merah lokal yang berasal dari kabupaten Nganjuk, Probolinggo, Malang dan Kediri memiliki kualitas yang cukup baik dan unggul dibanding dengan pesaing baik dari segi rasa, ketahanan dan bentuk. Keunggulan kompetitif bawang merah ini juga dipengaruhi oleh kualitas lahan yang ada, ketersediaan infrastruktur yang cukup lengkap dan keterampilan dari petani dalam mengolah lahan sehingga tercipta produk bawang merah yang berkualitas unggul dan berdaya saing. Maka dapat dikatakan bahwa kuantitas produksi bawang merah yang dihasilkan oleh empat kabupaten tersebut memiliki keunggulan kompetitif dari segi kualitas produk jika dibanding dengan pesaing yaitu bawang merah impor.

\section{Pengujian Pengaruh Langsung Relational Capital terhadap Supply Chain Integration}

\author{
$\mathrm{H}_{1}$ : Relational Capital berpengaruh signifikan terhadap Supply Chain \\ Integration.
}

Hasil analisis jalur membuktikan adanya pengaruh positif namun tidak signifikan antara Relational Capital $(\mathrm{X})$ terhadap Supply Chain Integration $\left(\mathrm{Y}_{1}\right)$. Diperoleh nilai koefisien beta sebesar 0,107 yang menunjukan bahwa terdapat pengaruh positif antara Relational Capital terhadap Supply Chain Integration sebesar 0,107. Nilai P-Value sebesar 0,130 menyatakan bahwa pengaruh Relational Capital terhadap Supply Chain 
Integration tidak signifikan karena nilai $\mathrm{P}$-value $>0,05$. Maka keputusannya adalah $\mathrm{H}_{0}$ diterima, berarti hipotesis yang menyatakan Relational Capital berpengaruh signifikan terhadap Supply Chain Integration ditolak. Hal tersebut dikarenakan petani selalu dirugikan oleh para tengkulak selaku penyalur dan pembeli bawang merah karena adanya asimetri informasi yang diterima oleh petani. Adanya konflik kepentingan yang terjadi antara petani dan tengkulak sehingga menyebabkan informasi yang diberikan kepada petani tidak sepenuhnya sesuai dengan keadaan yang sebenarnya terjadi, terutama dalam hal harga. Oleh sebab itu, petani menjual hasil panen bawang merah dengan harga lebih rendah dibanding dengan harga pasar. Selain itu, petani tidak memiliki kekuatan dalam posisi tawar menawar.

Scott (1988) menjelaskan relasi yang terjadi antara petani dan tengkulak dengan gambaran hubungan patron-klien yaitu relasi yang terjadi antara petani dan tengkulak yang belum berjalan dengan baik yang disebabkan karena adanya perbedaan kepentingan antar kedua belah pihak. Hal ini dibuktikan dengan beberapa penelitian sebelumnya yang mengatakan bahwa relasi antara petani dan tengkulak masih belum berjalan dengan baik karena adanya perbedaan kepentingan (Fuad, 2015; Isna, 2014; Rustinsyah, 2011).

\section{Pengujian Pengaruh Langsung Relational Capital terhadap Competitive Advantage}

\section{H2: Relational Capital berpengaruh terhadap Competitive Advantage.}

Hasil analisis menunjukkan nilai koefisien beta sebesar 0,282 yang berarti bahwa terdapat pengaruh positif antara Relational Capital terhadap Competitive Advantage sebesar 0,282, dengan besarnya nilai P-value sebesar 0,000 maka dinyatakan adanya signifikansi antara Relational Capital terhadap Competitive Advantage karena nilai Pvalue $<0,05$. Keputusan yang dihasilkan adalah $\mathrm{H}_{0}$ ditolak, berarti hipotesis yang menyatakan Relational Capital berpengaruh terhadap Competitive Advantage diterima. Hal ini berarti dengan adanya pengaruh positif dan signifikan antara Relational Capital terhadap Competitive Advantage. Adanya Relational Capital yang tinggi pada petani terhadap mitranya maka akan membentuk Competitive Advantage, begitu juga sebaliknya jika semakin rendahnya Relational Capital maka Competitive Advantage tidak akan terbentuk.

\section{Pengujian Pengaruh Langsung Supply Chain Integration berpengaruh terhadap Competitive Advantage}

\section{$\mathrm{H}_{3}$ : Supply Chain Integration berpengaruh terhadap Competitive Advantage.}

Hasil analisis menunjukkan bahwa nilai koefisien beta sebesar 0,032 yang berarti bahwa terdapat pengaruh positif pada Supply Chain Integration terhadap Competitive Advantage sebesar 0,032, dengan nilai $\mathrm{p}$-value sebesar 0,596 ( $>>0,05)$ maka pengaruh pada Supply Chain Integration terhadap Competitive Advantage tidak signifikan. Sehingga keputusannya adalah $\mathrm{H}_{0}$ diterima, berarti hipotesis yang menyatakan Supply Chain Integration berpengaruh terhadap Competitive Advantage petani ditolak. Hal ini berarti bahwa dengan adanya Supply Chain Integration tidak akan berpengaruh secara signifikan terhadap terciptanya Competitive Advantage pada petani.

\section{Simpulan dan Saran}

Berikut adalah simpulan berdasarkan analisis data.

1. Relational Capital yang terjalin dengan baik antara petani dengan pemasoknya tidak akan mempengaruhi atau meningkatkan Supply Chain Integration bawang merah di 
Kabupaten Nganjuk, Kediri, Malang, dan Probolinggo. Adanya rantai pasok integratif dipengaruhi secara tidak signifikan oleh modal relasional karena modal relasional adalah hal yang sudah dilakukan petani sebelum terciptanya rantai pasok, meskipun relasi yang terbentuk masih tidak berjalan dengan baik karena adanya berbagai permsalahan yang terjadi seperti yang diuraikan oleh peneliti sebelumnya.

2. Supply Chain Integration tidak berpengaruh secara signifikan terhadap terciptanya Competitive Advantage petani bawang merah di Kabupaten Nganjuk, Kediri, Malang, Probolinggo, karena dengan Rantai Pasok Intergratif yang belum berjalan dengan baik maka aliran informasi, barang, dan uang didalam rantai pasokan tersebut tidak terjadi dengan efisien sehingga keunggulan kompetitif belum tercapai. Panjangnya rantai pasok pada tata niaga bawang merah di Kabupaten Nganjuk, Kediri, Malang dan Probolinggo menjadikan keunggulan komeptitif melalui rantai pasok integratif belum tercapai secara efisien sehingga perlu adanya efisiensi rantai pasok.

3. Supply chain integration yang belum tercipta dengan baik akibat relational capital petani terhadap tengkulak belum berjalan dengan baik dan perlu diperbaiki. Diperlukan kehadiran pemerintah dalam penentuan kebijakan yang mengatur mengenai harga, sehingga petani tidak lagi dirugikan. Selain itu, perlu adanya pembentukan sistem teknologi informasi yang efektif dan efisien secara up to date dan real time, agar informasi dapat diterima dengan baik oleh petani, konsumen dan pedagang

Berdasarkan temuan dalam penelitian ini, disarankan hal-hal berikut.

1. Pemerintah perlu menerapkan kebijakan yang mengatur mengenai harga jual petani terhadap tengkulak agar petani mengalami keuntungan saat menjual hasil panennya.

2. Petani perlu menjalin relasi yang baik dengan semua mitra baik pemerintah selaku pemberi kebijakan, supplier saprotan dan para pedagang atau pembeli bawang merah agar tercipta rantai pasok yang integratif.

3. Peneliti selanjutnya diharapkan menggunakan semua dimensi pada variabel modal sosial yaitu dimensi kognitif, struktural dan relasional serta dapat menambahkan variabel lainnya yang yang termasuk dalam komponen aktivitas praktek managemen rantai pasok sebagai aktivitas penerapan managemen rantai pasok yang baik. Misalnya saja information sharing, information quality, postponement, agreed vision and goals dll sebagai variabel tambahan untuk mendukung analisis.

4. Objek penelitian pada penelitian ini hanya dilakukan pada petani bawang merah, sehingga diharapkan peneliti selanjutnya dapat meneliti tidak hanya petani tetapi kepada pemasok obat, bibit, saprotan dan juga pengepul, pedagang sehingga informasi yang didapat lebih luas lagi.

\section{Daftar Pustaka}

Badan Pusat Statistik. 2018. Pertumbuhan Ekonomi Indonesia Triwulan I-2018 No. 40/05/Th.XXI.

Badan Pusat Statistik. 2015. Katalog. Distribusi Perdagangan Komoditas Bawang Merah Indonesia 2015

Barney, J. 1991. Firm resources and sustained competitive advantage. Journal of Management, 17(1), 99-120.

Barney, Jay. B., 2007. Gaining and Sustaining Competitive Advantage. New Jersey: Pearson Prentice-Hall. 
Boossabong P, Taylor MF. 2009. Impact of trade liberalization on the agricultural sector and adjustment policy: the case of shallot plantations in northeastern Thailand. Kasetsart J. (Soc. Sci) $30: 323-337$.

Collis, D.J., 1991. A Resource-Based Analysis Of Global Competition: The Case Of The Bearings Industry. Strategic Management Journal. 12 (1): . 49- 68.

Collins, J. D. Dan M. A. Hitt, 2006. Leveraging Tacit Knowledge In Alliances: The Importance Of Using Relational Capabilities To Build And Leverage Relational Capital. Journal Of Engineering And Technology Management, 23 (3): 147-167.

De Castro, G., M., And Saez, P. L., And Lopez, J., 2004. The Role Of Corporate Reputation In Developing Relational Capital. Journal Of Intellectual Capital, 5(1) 579-585.

Direktorat Jenderal Perdagangan Dalam Negeri Kementerian Perdagangan. Profil Komoditas Barang Kebutuhan Pokok Dan Barang Penting Komoditas Bawang. 2016

Dominick, Salvatore. 1997. Ekonomi Internasional. edisi 5 cetak 1. Erlangga, Jakarta

Eorter, Michae. 1993. Keunggulan Bersaing: Menciptakan dan Mempertahankan Kinerja Unggul. PT. Gramedia, Jakarta.

Esterhuizen, Dirk, J.V. Royen and Luc D'Haese. 2008. An Evaluation of The Competitiveness Sector in South Afrika. Advanced in Competitiveness Research 16(1-2): 31-46.

Fred R. David. 2009. Manajemen Strategis. Salemba Empat Jakarta .

Flynn, B.B., Huo, B. \& Zhao, X., 2010. The Impact Of Supply Chain Integration On Performance: A Contingency And Configuration Approach. Journal of Operations Management, 28(1), Pp.58-71.

Fuad, Zainul, Aenurofik Dan Rosyid, 2015. Belenggu Tengkulak Atas Pembudidaya Lele: Relasi Patron-Klien Budidaya Lele Di Wono Tunggal Jawa Tengah. Jurnal Hukum Islam (JHI), 13(2): 88-98.

Fransiskus Randa dan Ariyanto Solon. 2012. Pengaruh Modal Intelektual Terhadap Nilai Perusahaan (Studi Empiris pada Perusahaan Manufaktur yang Terdaftar di Bursa Efek Indonesia). Jurnal Sistem Informasi Manajemen dan Akuntansi, Vol 10 No 1 April 2012, Fakultas Ekonomi UAJ Makassar, 2012, hal. 29

Frohlich, M. T. \& Westbrook, R., 2001. Arcs Of Integration: An International Study Of Supply Chain Strategies. Journal Of Operations Management, 19, 185-200.

Hamidin, Dini Dan Surendro, K. 2010. Model Supply Chain Management Dalam Perspektif Teknologi. Seminar Dan Call For Paper Munas Aptikom

Hitt, M.A., Ireland, R.D., Hoskisson, R.W. 2001. Strategy Management Competitiveness And Globalization. West Publishing Company. 
Inda Sukati, dkk. 2012. Competitive Advantage Through Supply Chain Responsiveness And Supply Chain Integration. Faculty Of Management And Human Resource Development Universiti Teknologi Malaysia. International Journal Of Business And Commerce 1( 7): Mar 2012[01-11]

Indriantoro Dan Supomo. 2009. Metode Penelitian Bisnis. Edisi Pertama. Yogyakarta: BPFE.

Johanisson, B., 1998. Personal Networks In Emerging Knowledge-Based Firms: Spatial And Functional Patterns. Entrepreneurship And Regional Development, 10. 297-312

Kale, P., Singh, H., Perlmutter, H., 2000. Learning And Protection Of Proprietary Assets In Strategic Alliances: Building Relational Capital. Strategic Management Journal. 21 (2), 217-228.

Kementrian Pertanian Republik Indonesia. 2015. Outlook Komoditi Bawang Merah 2015. (Online) Di Unduh Dari: Http ://Epublikasi.Setjen.Pertanian.Go.Id /Epublikasi/Outlook/2015/Outlook_Horti/Outlook_Bawangmerah_2013/Files/As sets/Downloads/Publication.Pdf ( 3 Oktober 2018)

Luthans, Fred, Youssef, Carolyn M., Avolio, Bruce J., 2007. Psychological Capital :Developing The Human Competitive Edge. New York : Oxford Uiversity Press

Mata, F., W. Fuerst, And J. Barney, 1995. Information Technology And Sustained Competitive Advantage: A Resource-Based Analysis. MIS Quarterly 19(4), 487-505.

Moeheriono. 2012. Pengukuran Kinerja Berbasis Kompetensi. Jakarta: Raja Grafindo Persada.

Moran, Florencia., Palmer, David., Borstoff, Patricia C. 2007. An exploratory analysis of the

relationship between organizational culture, regional culture, causal ambiguity and competitive advantage in an international setting. Journal of International Business Research, Vol. 6, No. 1

Morissan. 2012. Metode Penelitian Survei. Jakarta: Prenada Media Group.

Nazir, Mohammad. 2014. Metode Penelitian Bisnis. Bogor: Ghalia Indo.

Ngah, Rohana And Ibrahim, Abdul Razak, 2009. The Relationship Of Intellectual Capital,

Innovation Dan Organizational Performance: A Preliminary Study In Malaysian SMEs. International Journal Of Management Innovation Systems Vol. 1 No. 1:E1, Pp. 1-13.

O'Leary, BS, Lindholm, ML, Whitford, RA, Freeman, SE., 2002. Selecting The Best And Brightest: Leveraging Human Capital. Human Resource Management, Fall, Vol. 41, No. 3, Pp. 325-340.

Porter ME. 1999. The Competitive Advantage of Nations. New York (US): The Free Press.

Pujawan, I. 2005. Supply Chain Management. Surabaya: Guna Widya. 
Pusat Pengkajian Perdagangan Dalam Negeri Badan Pengkajian Dan Pengembangan Perdagangan Kementerian Perdagangan Republik Indonesia. 2017. Analisis Perkembangan Harga Bahan Pangan Pokok Di Pasar Domestik Dan Internasional

Pusat Data Dan Sistem Informasi Pertanian Sekretariat Jenderal - Kementerian Pertanian. 2015. OUTLOOK BAWANG MERAH

Reefke, H., Sundaram, D., 2016. Key Themes And Research Opportunities In Sustainable Supply Chain Management - Identification And Evaluation. Omega 66, 1-17.

Roos, Goran and Roos, Johan, 1997. Measuring your Company's Intellectual Performance, International Journal of Strategic Management: Long Range Planning. Vol. 30 No. 3, pp. 413-426

Saa-Perez \& Garcia-Falcon. 2002. A Resource-Based View Of Human Resource Management And Organizational Capabilities Development. International Journal Of Human Resource Management, Vol. 13, No.1, PP. 123-140

Salvador, Fabrizio., Cipriano Forza, Manus Rungtusanatham, Thomas Y. Choi. 2001. Supply

Chain Interactions And Time-Related Performances: An Operations Management Perspective. International Journal Of Operations \& Production Management, Vol. 21 No. 4, 2001, Pp. 461-475.

Sarason, Yolanda dan Tegarden, Linda F. (2003). The Erosion of the Competitive Advantage of Strategic Planning: A Configuration Theory and Resource Based View. Journal of Business and Management, Vol. 9, No1.

Schoenherr T, Swink M. 2011. Revisiting The Arcs Of Integration : Cross-Validations And

Extensions. Journal Of Operations Management. 30:99-115.

Schoenherr, T. \& Swink, M., 2012. Revisiting The Arcs Of Integration: CrossValidations And

Extensions. Journal Of Operations Management, 30(2), Pp.99-115

Setiawan, Ahmad Ikhwan Dan Reza Rahardian. 2005. Pengaruh Pola Integrasi Supply Chain

Management Terhadap Performa Perusahaan Pada Industri Jasa Makanan Di Surakarta. Jurnal Bisnis \& Manajemen. Vol 05, No.1

Siagian. Yolanda M. 2005. Aplikasi Supply Chain Management Dalam Dunia Bisnis. Jakarta : Grasindo

Simchi-Levi, D., Kaminsky, P., Simchi-Levi, E., \& Bishop, W. 2003. Designing And Managing The Supply Chain. Boston: Mcgraw-Hill

Simchi-Levi, D., Kaminsky, P., \& Simchi-Levi, E. 2004. Managing The Supply Chain: The Definitive Guide For The Business Professional. New York: Mcgraw-Hill. 
Siti Nur 'Atikah Zulkiffli Dan Nelson Perera. 2011.The Influence Of Levels Of Supply Chain Integration On The Relationship Between Corporate Competitive Capabilities And Business Performance: Evidence From Malaysian SMEs. University Of Wollongong. Sydney Business School - Papers

Strandskov, Jesper. 2006. Sources of competitive advantages and business performance. $\underline{\text { Journal of Business Economics and Management. Volume 7, } 2006 \text { - Issue } 3}$

Sugiyono. 2010. Metode Penelitian Pendidikan Pendekatan Kuantitatif, Kualitatif dan $R \& D$.

Bandung: Alfabeta

Susanto, AB. 2014. Manajemen Strategik Komprehensif. Erlangga. Jakarta.

Tim Pemantauan Dan Pengendalian Inflasi (TPI) Kelompok Kerja Nasional Tim Pengendalian Inflasi Daerah (Pokjanas TPID). 2016. Inflasi 2016 Cukup Rendah Dan Berada Dalam Batas Bawah Sasaran Inflasi Bank Indonesia.

Teece, D., Pisano, G., \& Shuen, A. 1997. Dynamic Capabilities And Strategic Management . Strategic Management Journal. Vol. 18: Pg. 509-533.

Tewu. M. E. 2015. Peranan Sumber Daya Manusia Dalam Meningkatkan Aktivitas Kelompok Tani Di Desa Tember. E-Journal “Acta Diurna” Volume IV. No.3. Tahun 2015.Tjiptono, Fandy. 2007. Strategi Pemasaran. Edisi Kedua. Yogyakarta : Andi.

Turban, E., King, D., Mckay, J., Marshall, P., Lee, J., \& Viehland, D. 2008. Electronic Commerce 2008 A Managerial Perspective. New Jersey: Pearson Education, Inc.

Van Der Vorst J. G. A. J., 2004.Supply Chain Management: Theory And Practices, The Emerging World Of Chains \& Networks. Elsevier, Hoofd-Stuk 2.1, Wageningen.

Van Der Vaart, Taco; Cristina Gimenez; Dan Dirk Pieter Van Donk. 2012. Supply Chain Integration And Performance: The Impact Of Bussiness Conditions. University Of Groningen.

Welbourne, T.M., 2007. Employee Engagement: Beyond The Fad And Into The Executive Suite. Executive Forum.

Welbourne T.M. 2008. Relational Capital: Strategic Advantage For Small And MediumSize Enterprises (Smes) Through Negotiation And Collaboration. Journal Of Business Economy, 18(5): 438-492.

Wenli, Li , Paul K. Humphreys, Andy C.L. Yeungc, T.C. Edwin Cheng. 2007. The Impact Of Specific Supplier Development Efforts On Buyer Competitive Advantage: An Empirical Model. Int. J. Production Economics 106 (2007) 230-247

Wernerfelt, B. 1984. A Resource-Based View Of The Firm. Strategic Management Journal, 171-180.

Wernerfelt Birger. 1995. The Resource Based View of The Firm: Ten Years After. Strategic Management Journal, 16( 3), 171-174. 
Wilk, E.D., And Fensterseifer, J.E. 2003. Use Of Resource-Based View In Industrial Cluster Strategic Analysis. International Journal Of Operations \& Production Management. Vol. 23: 995.

Yubing Yu \& Baofeng Huo. 2017. The Impact Of Relational Capital On Supplier Quality Integration And Operational Performance. Alogistics And E-Commerce College, Zhejiang Wanli University, Ningbo, People's Republic Of China; Bschool Of Management, Zhejiang University, Hangzhou, People's Republic Of China. Total Quality Management, 2017.

Yulliatin. 2008. Pengembangan Indikator Penilaian Kinerja Supply Chain Pada Proyek Konstruksi Bangunan Gedung. Tesis Magister Manajemen Dan Rekayasa Konstruksi, Institut Teknologi Bandung. 
